\title{
Abdominal aortic aneurysm repair with a functional autotransplanted kidney
}

\author{
Jason Lee, MD; ${ }^{*}$ Andrew D. Dueck, MD; ${ }^{*}$ Alan G. Lossing, MD; ${ }^{*}$ Robert J. Stewart ${ }^{t}$
}

\begin{abstract}
During the course of their practice, most urologists will encounter only a few patients with renal autotransplants. Even fewer will encounter those with renal autotransplants requiring abdominal aortic aneurysm (AAA) surgery. Although there is some literature describing AAA surgery in renal allotransplant patients, there is little such literature regarding AAA surgery in patients with autotransplanted kidneys. We present a case of a patient with a single, functioning, autotransplanted kidney who required AAA surgery. We also discuss the issue of the need for renal protection.
\end{abstract}

CUAJ 2007;1(3):291-3

\section{Introduction}

With advancements in kidney transplantation and improved longterm allograft survival, ${ }^{1}$ the once rare clinical scenario of an abdominal aortic aneurysm (AAA) in a patient with a functioning renal allograft has become much more familiar. ${ }^{2-5}$ Despite increasing numbers of case reports describing such scenarios, to date, the repair of AAAs in patients with autotransplanted kidneys is not well described in the literature. ${ }^{6}$

In both allograft and autograft patients, AAA repair has the potential to cause irreversible ischemic injury. Two distinct approaches have been described to address this issue: methods that depend on expeditious surgery alone and those that use a specific form of renal protection. Some examples of such strategies include cold renal perfusion, general hypothermia, indwelling shunts, axillo-femoral bypass grafts and endovascular stent grafting..$^{2-5}$ We report a case of a 69-yearold female with a $6.0-\mathrm{cm}$ AAA and an autotransplanted right pelvic kidney.

\section{Case Report}

A 69-year-old female, while being investigated by her family physician for a recent history of general malaise and mild dyspnea, was found to have bilateral complex cystic and solid lesions on abdominal ultrasound. In addition, a 6.0-cm infrarenal AAA was also identified (Fig. 1). The patient's past medical history was also significant for hypertension, coronary artery disease, appendectomy and cholecystectomy.

She went on to have an abdominal CT scan that demonstrated bilateral lesions highly suggestive of cystic renal cell carcinoma. There was a 7.0-cm exophytic lower pole lesion in the left kidney and a 4.0-cm central lesion in the interpolar region of the right kidney (Fig. 2 and Fig. 3).

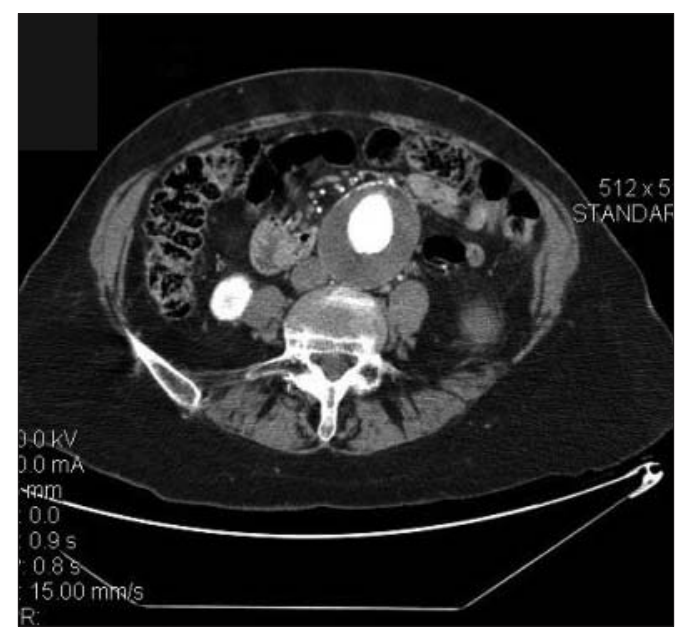

Fig. 1. Contrast-enhanced CT angiogram. The axial slice demonstrates a $6-\mathrm{cm}$ infra-renal abdominal aortic aneurysm.

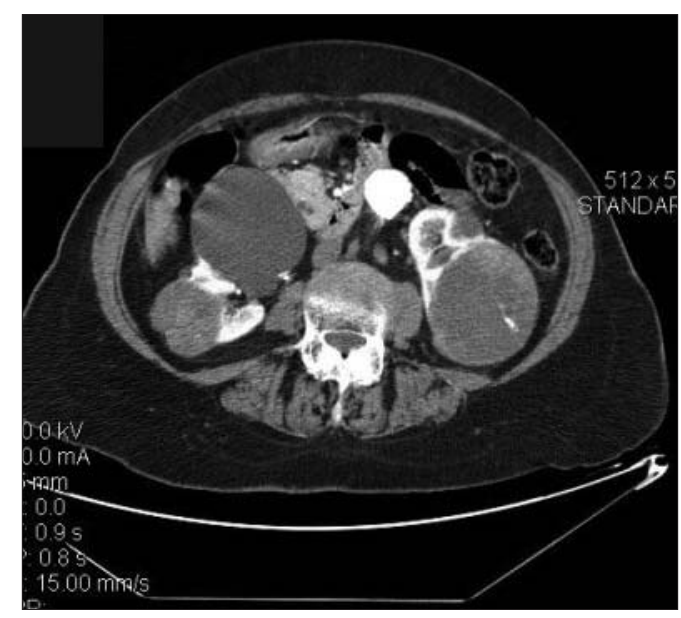

Fig. 2. Contrast-enhanced abdominal CT. The axial slice demonstrates a $7-\mathrm{cm}$ cystic renal cell carcinoma in the left kidney and a 4-cm right cystic renal cell carcinoma with a $10-\mathrm{cm}$ simple cyst in the right kidney. 
The initially planned partial left nephrectomy was converted to a radical nephrectomy, intraoperatively, owing to significant interval growth of the tumour since the last imaging. Approximately 6 weeks later, the patient underwent a right radical nephrectomy with ex vivo partial nephrectomy, renal reconstruction and autotransplantation into the right iliac fossa. Postoperatively, she briefly required renal replacement therapy but convalesced well and was discharged from hospital with a creatinine of $190 \mu \mathrm{mol} / \mathrm{L}$.

Seven months later, she was admitted to hospital for elective repair of her 6.0-cm AAA. On admission, her creatinine was $140 \mu \mathrm{mol} / \mathrm{L}$. To minimize operative ischemic injury an external, 8.0-mm Dacron, right axillo-femoral bypass graft was placed before cross clamping of the aorta. This was left extracorporeal and was not tunneled subcutaneously. The AAA was then repaired without complication using a 16.0-mm Dacron tube graft. Throughout the repair the autotransplanted kidney was perfused via the retrogradely directed right axillo-femoral bypass graft, which was subsequently removed without incident.

Postoperatively the patient recovered without the need for renal replacement therapy. Her creatinine level reached a peak of $171 \mu \mathrm{mol} / \mathrm{L}$ on postoperative day 1 and returned to baseline by postoperative day 4 . She was discharged from hospital with a creatinine of $131 \mu \mathrm{mol} / \mathrm{L}$.

\section{Discussion}

Aortic surgery following renal allograft transplan-

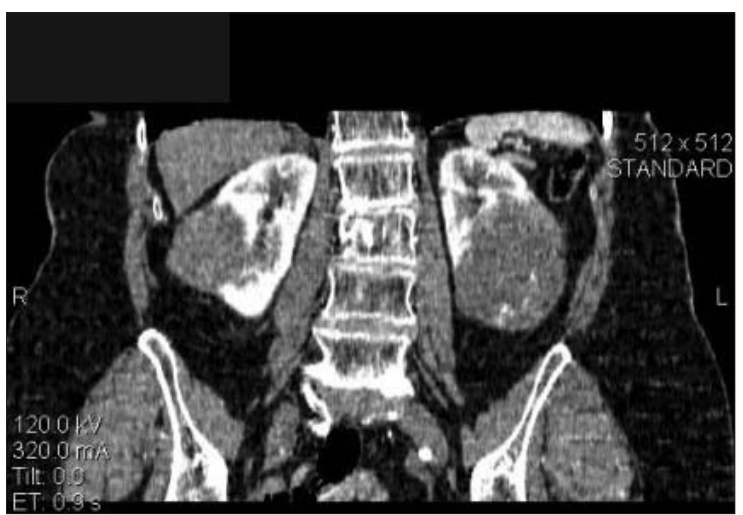

Fig. 3. Contrast-enhanced abdominal CT. The coronal slice demonstrates a $7-\mathrm{cm}$ left cystic renal cell carcinoma and a 4-cm right cystic renal cell carcinoma. tation, and in particular renal autotransplantation, is uncommon. However, with improvements in renal surgery and transplant immunosuppressive regimes it is becoming a clinical entity of increasing relevance to urologists and vascular surgeons.

With no collateralization and a single arterial supply, the risk of irreversible renal damage due to warm ischemia that applies to an allograft kidney during an AAA repair is also present for autotransplanted kidneys.

To address this risk, a number of authors have recommended some form of renal protection during aortic cross-clamping. ${ }^{7-10}$ Most of the techniques described, however, require an additional procedure and prolong operative times. As such, several authors have argued that renal protection is not required during aneurysm repair and that expeditious surgery and retrograde perfusion alone are sufficient to prevent ischemic injury. ${ }^{11-16}$ Although evidence does suggest that renal protection is not required in all cases, some form of renal protection may be important when aortic reconstruction is expected to be difficult or if there is an element of renal insufficiency to suggest significant sensitization to warm ischemia.

After left radical nephrectomy and ex vivo partial nephrectomy, renal reconstruction and autotransplantation of her right kidney, our patient was left with a significantly reduced renal mass. Investigations before the AAA repair revealed mild proteinuria and some early evidence of hyperfiltration nephropathy. Despite the fact that in this setting renal protection may have prolonged the operative time, it may have prevented ischemic insult leading to a decline in renal function.

\section{Conclusion}

With significant medical and surgical improvements surrounding renal surgery and transplantation, the occurrence of AAAs in the setting of transplanted kidneys, both allograft and autograft, will become more frequent. With no accepted protocol in aneurysm repair, the use of renal protection should be determined on a case by case basis. In specific circumstances, the use of an axillo-femoral bypass graft to maintain renal perfusion during AAA repair may avoid irreversible ischemic injury to an autotransplanted kidney and prevent long-term graft damage. 
From St. Michael's Hospital and the Department of Surgery, ${ }^{\star}$ Division of Urology and †Division of Vascular Surgery, University of Toronto, Toronto, Ont.

This article has been peer reviewed.

Competing interests: None declared.

\section{References}

1. Brennan DC. Long-term trends in allograft suvvival. Adv Chronic Kidney Dis 2006;13:11-7.

2. Favi $E$, Citterio $F$, Tondolo $V$, et al. Abdominal aortic aneurysm in renal transplant recipients. Transplant Proc 2005;37:2488-90.

3. Roach DM, Thompson MM, Patrick GM, et al. Aortic aneurysm repair with a functioning renal transplant: therapeutic options. ANZ I Surg 2004;74:65-7.

4. Martin-Conejero A, Serrano-Hernando FJ, Reina-Gutierrez T, et al. Surgery for aortoiliac aneurysm after kidney transplant. Transplant Proc 2003;35:2953-7.

5. Skelly CL, Farmer AJ, Curi MA, et al. Aortic reconstruction in patients with functioning renal allografts. Ann Vasc Surg 2002;16:779-83.

6. Neelakandhan KS, Muralidhar R, Unnikrishnan M, et al. Abdominal aortic aneurysm repair in a patient with bilateral autotransplanted kidneys. Thorac Cardiovasc Surg 1994; 42:128-30.

7. Wolf $W$, Ayisi $K$, Ismail $M$, et al. Abdominal aortic aneurysm repair after renal trans- plantation with extracorporeal bypass. Thorac Cardiovasc Surg 1991;39:384-5.

8. Hughes JD, Douglas JM, Charles FS. Renal transplant perfusion during aortoiliac aneurysmectomy. J Vasc Surg 1985;2:600-2.

9. Panneton JM, Gloviczki P, Canton LG, et al. Aortic reconstruction in kidney transplant recipients. Ann Vasc Surg 1996;10:97-108.

10. Chacko KN, Ninan S, Jacob CK, et al. Transplant kidney protection during aortic aneurysm surgery. J Urol 1999;161:891-2.

11. Harris JP, May J. Successful aortic surgery after renal transplantation without protection of the transplanted kidney. J Vasc Surg 1987;5:457-67.

12. Hakim NS, Koffman G, Taylor P. Repair of abdominal aortic aneurysm after renal transplantation without renal protection. Br J Clin Pract 1994;48:220-1.

13. Boudreaux JP, Wolma FJ, Fich JC. Abdominal aortic repair after renal transplantation without extracorporeal bypass. Transplant Proc 1990;22:403-4.

14. Jivegard L, Holm J. Repair of abdominal aortic aneurysm in renal transplant patient. Eur J Vasc Surg 1992;6:226-7.

15. Gouny $P$, Lenot $B$, Decaix $B$. Aortoiliac surgery and kidney transplantation. Ann Vasc Surg 1991;5:26-31.

16. Lacombe M. Abdominal aortic aneurysmectomy in renal transplant patients. Ann Surg 1986;203:62-8.

Correspondence: Dr. Jason Lee, St. Michael's Hospital, 55 Queen St. E., Toronto

ON M5C 1R6; jasonjason.lee@utoronto.ca
We accept events for the Calendar section. You may send them to us in the following ways:

\section{E-mail journal@cua.org}

Fax

$514875-0205$
Mail
CUÄ
1155 University Ave.,
Suite 1014
Montréal, QC H3B 3A7

\section{CALENDAR}

\section{Thomas \& Alice Morgans Fear Memorial Conference on Voiding Dysfunction \& the Aging Population}

October 27-28, 2007

Multidisciplinary conference

Dalhousie University

Division of Urology, Halifax, Nova Scotia

International faculty of high quality

Contact: Debbie Lewis-Boyce

Phone: 902-473-5853

Email: Debbie.lewisboyce@cdha.nshealth.ca

Space is limited to the first 200 participants only so registration is a MUST.

\section{First International Workshop on Focal Therapy and Imaging of Prostate Cancer}

February 22-23, 2008

Duke University Medical Center, Durham, NC, USA

Contact person: Mrs. Rae Sidlauskas

E-mail: rachel.sidlauskas@duke.edu

Phone: 919 684-2033

Fax: 919 684-4611

Web site: urology.surgery.duke.edu 